\title{
Low incidence of clonality in cold water corals revealed through the novel use of standardized protocol adapted to deep sea sampling
}

\author{
Becheler Ronan ${ }^{1}$, Cassone Anne-Laure ${ }^{1}$, Noël Philippe ${ }^{1}$, Mouchel Olivier ${ }^{1}$, Morrison Cheryl L. ${ }^{3}$, \\ Arnaud-Haond Sophie ${ }^{1,2, *}$
}

${ }^{1}$ Ifremer, EEP-LEP, Centre de Brest. Site du Technopôle, 29480 Plouzané; France

2 Ifremer, MARBEC, Centre de Sète, Bd Jean Monnet, BP 171, 34203 Sète Cedex; France

${ }^{3}$ U.S. Geological Survey, Leetown Science Center, National Fish Health Research Laboratory, 11649

Leetown Rd., Kearneysville, WV 25430, USA

* Corresponding author : Sophie Arnaud-Haond, email address : Sophie.Arnaud@ifremer.fr

\begin{abstract}
:
Sampling in the deep sea is a technical challenge, which has hindered the acquisition of robust datasets that are necessary to determine the fine-grained biological patterns and processes that may shape genetic diversity. Estimates of the extent of clonality in deep-sea species, despite the importance of clonality in shaping the local dynamics and evolutionary trajectories, have been largely obscured by such limitations. Cold-water coral reefs along European margins are formed mainly by two reef-building species, Lophelia pertusa and Madrepora oculata. Here we present a fine-grained analysis of the genotypic and genetic composition of reefs occurring in the Bay of Biscay, based on an innovative deep-sea sampling protocol. This strategy was designed to be standardized, random, and allowed the georeferencing of all sampled colonies. Clonal lineages discriminated through their Multi-Locus Genotypes (MLG) at 6 to 7 microsatellite markers could thus be mapped to assess the level of clonality and the spatial spread of clonal lineages. High values of clonal richness were observed for both species across all sites suggesting a limited occurrence of clonality, which likely originated through fragmentation. Additionally, spatial autocorrelation analysis underlined the possible occurrence of finegrained genetic structure in several populations of both L. pertusa and M. oculata. The two cold-water coral species examined had contrasting patterns of connectivity among canyons, with among-canyon genetic structuring detected in M. oculata, whereas L. pertusa was panmictic at the canyon scale. This study exemplifies that a standardized, random and georeferenced sampling strategy, while challenging, can be applied in the deep sea, and associated benefits outlined here include improved estimates of fine grained patterns of clonality and dispersal that are comparable across sites and among species.
\end{abstract}

Keywords : Cold-water coral, Lophelia pertusa, Madrepora oculata, Clonality, Fine-grained spatial genetic structure, Standardized sampling 


\section{Introduction}

Limited accessibility of the deep sea represents a major obstacle for scientific research. In particular, conducting a rigorous sampling strategy is de facto challenging. This logistical difficulty partly explains gaps in our knowledge of major ecological and/or evolutionary trends shaping the evolution and dynamics of deep sea species and populations (but see Pawlowski et al., 2007; Van Dover et al., 2002; Vrijenhoek, 1997; Won et al., 2003), though recent improvements in technology have increased access to deep sea ecosystems. Notably, the empirical studies dedicated to fine-grained patterns of relatedness and associated key processes (such as spatial distribution of MLGs and recruitment) within populations often require standardized and high density sampling to allow thorough understanding of small scale distribution and dynamics and rigorous inter-site comparisons. Yet, standardization of sampling strategies is rare because the collection of samples is time consuming and technically difficult.

Among deep sea ecosystems discovered during recent decades, cold-water coral (CWC) reefs have been the subject of increasing research efforts to improve our understanding of their extent and role in supporting biodiversity along continental margins. Despite recent efforts, exploration of CWC reefs remains preliminary and fragmentary. These organisms represent the structural basis of key deep ecosystems, forming important three dimensional biological structures (Rogers, 1999). Similar to their shallow-water counterparts, CWC reefs support high biodiversity and biomass (Freiwald et al., 2004; Roberts et al., 2006), providing habitat and nursery for numerous marine species (Baillon et al., 2012). Recently, it has been demonstrated that these ecosystems constitute underappreciated hotspots for carbon and nutrient cycling along continental margins (Cathalot et al., 2015). Cold-water coral reefs are distributed worldwide (Cairns, 1994; Zibrowius, 1980), and are particularly prevalent along the European Atlantic continental margin (Freiwald and Roberts, 2005). They are generally reported at depths between 200 and 1000 meters, but occasionally are found as shallow as 35 and as deep as 4000 meters. The two main reef-building CWCs are the species Lophelia pertusa and Madrepora oculata, which co-exist in most of the reefs observed in the Northeastern Atlantic Ocean (Arnaud-Haond et al., 2015). These two widely distributed species are known for being partially clonal, i.e. able to alternate between sexual reproduction through the production of gametes, and asexual, vegetative growth through fragmentation (Roberts et al., 2006). In some locations, such as along the European continental margin (Freiwald et al., 1999) and off the southeastern United States (Ross and Nizinski, 2007), L. pertusa and M. oculata form large carbonate mounds, or reef bioherms, composed of carbonate mud and the skeletal remains of the corals (Roberts et al., 2006). Such bioherms allow corals to grow in an elevated position in the water column where faster flowing waters deliver increased levels of organic particulate food supply (Freiwald, 2002). 
In CWC, sexual reproduction occurs either in the water column or in the maternal colony through the fertilization of eggs. Gametes then develop into planula larvae that are dispersed via the water column. Their post-dispersal recruitment initiates the formation of a colony, corresponding to a unique genetic individual, as observed for the coastal gorgonian Corallium rubrum (Costantini et al., 2007a; Costantini et al., 2007b). Clonal reproduction is expected to occur through the fragmentation of colonies, where broken fragments form new colonies. This mimics the phenomenon of clonal elongation, which is well known for terrestrial and marine plants (Arnaud-Haond et al., 2012; Douhovnikoff et al., 2005; Schmid and Harper, 1985).The release of ameiotic larvae may represent a second source of clonal reproduction, although Dahl et al., (2012) suggest that asexually produced larvae do not occur in L. pertusa. Fragmentation leads to the potential for multiple occurrences of a genet, a unique genetic individual, occurring in different geographic locations as ramets deriving from a common sexual event (sensu Eriksson (1993). Partial clonality deeply influences the population dynamics and evolutionary trajectories, including the ability to disperse, occupy space and colonize new environments during periods of climate change, or to recolonize depleted environments such as reefs heavily impacted by deep sea trawling (Fossa et al., 2002; Roberts and Hirshfield, 2004). Notably, this life-history trait impacts the fine-grained (i.e. intra-population) genotypic and genetic structure, as shown for both terrestrial (Vekemans and Hardy, 2004) and marine species (Becheler et al., 2010; Blanquer et al., 2009; Dahl et al., 2012; Hammerli and Reusch, 2003; Shurin et al., 2009), through spatial competition among established clones and equilibrium between migrant recruitment and vegetative growth. Statistical descriptors of clonality are largely influenced by sampling scheme and strategy (Arnaud-Haond et al., 2007) and relevant assessment of clonal features requires standardized sampling. The extent of clonality and the estimate of fine-grained genetic structure should account for multiple occurrences of identical genotypes (ramets). It is therefore necessary to obtain geographical information for each sampling unit (Arnaud-Haond et al., 2007).

Although the literature on clonal reproduction is abundant for shallow-water corals (Baums et al., 2014; Baums et al., 2006; Boulay et al., 2012; Coffroth and Lasker, 1998; Foster et al., 2007; Hunter, 1993; Pinzón et al., 2012), very few studies have thus far addressed the issue of clonal versus sexual reproduction in CWC. An assessment of the degree of clonality, in Eastern North Atlantic L. pertusa reefs, suggests highly variable levels of clonal richness among sites, from cases in which all colonies exhibit distinct genotypes, to the other extreme where most colonies originated from the same clonal lineage and share the same multi-locus genotype (MLG) (Le Goff-Vitry et al., 2004). The highest rates of clonality could not be explained by edge effects of species range known to favor a high rate of clonality (Alberto et al., 2005; Baums et al., 2006), as the studied sites were well within the range of L. pertusa populations. Furthermore, samples were obtained via blind trawling so observations may have accurately reflected among-site variation of clonality, but may have been due to the technical artifact of analyzing distinct parts of a single colony fragmented during the trawling, leading to a) an 
overestimation of intra-site clonality and b) a possible associated overestimation of genetic structure among reefs. In contrast, a local and thorough analysis of a deep reef in Sweden that was exhaustively sampled with geolocation of colonies to map clonal lineages, showed extensive clonal elongation reaching tens to hundreds of meters (Dahl et al., 2012). However, this last study reported results for a single reef of $L$. pertusa, therefore, the extent of clonality for this species and its variation across larger spatial scales remains poorly understood. No genetic studies performed on M. oculata exist. Here, we aimed to:

1. Propose a realistic and tested sampling strategy and protocol for deep sea organisms, involving georeferenced sampling according to random coordinates in quadrats of standardized shape and size

2. Characterize the spatial pattern and extent of clonality in both L. pertusa and M. oculata reefs at the scale of the Bay of Biscay, using seven and six microsatellites markers, respectively, to discriminate MLGs

3. Present an analysis of the regional and fine-grained spatial genetic structure within and among reefs. 


\section{Material and methods}

\section{Study sites}

The continental slope of the Bay of Biscay is regularly cut by a succession of canyons connecting the continental shelf and the abyssal plain. In this area, CWC reefs are typically located between 600 and 900 meters depth, standing mostly above soft sediment. In general, reefs in Bay of Biscay are relatively sparse, with heterogeneous density, while size of colonies varies among sites. Eight canyons were explored and sampled during the BobEco cruise (September/October 2011; Figure 1). Despite their distance from the coast (approximately $150 \mathrm{~km}$ ), variable and sometimes intense evidence of fishing activity was observed in the canyons. Corals were sampled from five of these canyons (Figure 1) using the strategy detailed below.

\section{Sampling strategy and assessment of colony-densities}

CWC colonies were collected using the Remotely Operated Vehicle (ROV) Victor 6000 (Ifremer, France, Figure 2). A 100x200 $\mathrm{m}^{2}$-sampling quadrat was first defined and placed on the topographic map used to guide driving and collection in the ROV control cabin, with 30 GPS coordinates randomly generated within this quadrat and identified as particular points on the map. In the Guilvinec and Petite Sole Canyons, two quadrats were designed. For each geographical coordinate, one to three colonies of both L. pertusa and M. oculata were sampled using the manipulator of the ROV (explaining why the sampling size sometimes exceeded 30). Distinct colonies were collected at the same GPS coordinate by targeting different species and different color morphs for the same species or colonies that were separated by $0.5 \mathrm{~m}$ to $2 \mathrm{~m}$. When landing of ROV was impossible due to escarped seabed or high density of coral colonies, or when no colony was available for sampling at the predetermined random coordinate, the closest adjacent point was sampled and a geo-reference of each sample was corrected during the ROV-dive.

Each sampling unit (SU) originated from an identifiable colony. When colonies were broken, distinct fragments were not included in the analysis, in order to prevent overestimation of clonality or the admixture of cryptic but distinct colonies. Once a piece of colony was detached using the ROV manipulator, it was placed in one of the eight individually labelled boxes in a uniquely constructed "coral-case" (Figure 2, C) that were stored in the drawer of the ROV. Each position in the coral case was then assigned the spatial coordinate of the sampling point. As genetic studies require a relatively high number of samples, three coral cases were used for each dive, sometimes twice. Once a coral case was full, the ROV placed it in a buoyant lift (Figure 2, D) previously positioned in the immediate proximity of the sampling area. Once on the deck, each sample was isolated, 5-10 polyps were 
immediately processed for DNA extraction on board the ship, and the other portion was preserved in 96\% Ethanol for back-up. All DNA extractions and vials containing the archived tissue in ethanol were named according to the unique dive code (three digits) and the coral case in which they were collected.

In addition, the density of L. pertusa and M. oculata colonies was assessed within each sampling quadrat according to a standardized video analysis that was fully described in Arnaud-Haond et al., (2015) in this issue.

\section{DNA extraction, microsatellite amplification and loci scoring}

DNA extraction of M. oculata samples was performed on fresh tissue, using a classical CTAB method (Doyle and Doyle, 1988). For each colony, a branch around $5 \mathrm{~cm}$ in length was crushed and placed in a $2 \mathrm{~mL}$ tube, containing $480 \mu \mathrm{L}$ of CTAB buffer, and $20 \mu \mathrm{L}$ of proteinase $\mathrm{K}\left(20 \mathrm{ng} . \mu \mathrm{L}^{-1}\right)$. For $L$. pertusa samples, this protocol used for on-board extractions did not provide a sufficient quality of extracted DNA. Thus, 5 to 10 polyps of each sample stored in $96^{\circ}$-ethanol were dried overnight to further extract DNA using the Fast DNA $® S P I N$ kit for soil according to the protocol provided by the manufacturer (MP Biomedicals, France).

For L. pertusa, 7 microsatellite loci among the 13 proposed by Morrison et al., (2008) were chosen and amplified using the protocol published in Dahl et al., (2012), except a $55^{\circ} \mathrm{C}$ annealing temperature was used for the present study. PCR products were visualized using the ABI-3100 FNVR automated sequencer (Applied Biosystems) and scored using Geneious v5.6.4 (Biomatters $\left.{ }^{\circledR}\right)$.

For M. oculata, 6 microsatellite loci developed by author (Cheryl Morrison) were utilized (Supplementary Table S1, GenBank accession: KF944311, KF944317, KF944323, KF944330, KF944331, KF944344). A protocol similar to that used for L. pertusa was used to amplify and score the M. oculata loci. Two independent readings were done in order to minimize scoring errors, and corrections were applied when needed, including additional checking of the chromatograms and repeating amplification if the reading was still questionable.

\section{Genotypic and genetic analyses}

For both M. oculata and L. pertusa, the power of microsatellite datasets allowed distinction of clones on the basis of the MLGs of each sampling unit (Arnaud-Haond et al., 2005). First, allelic frequencies were assessed using the round-robin method (Parks and Werth, 1993), in order to avoid the overestimation of the frequency of rare alleles. The probability that two identical MLGs originate from distinct reproductive events, noted $P_{s e x}\left(F_{i s}\right)$, was assessed, taking into account departures from the Hardy-Weinberg $\left(F_{\text {is }}\right)$ according to the recommendation of Arnaud-Haond et al., (2007). When $P_{\text {sex }}\left(F_{i s}\right)<0.01$, the two identical MLGs were considered to belong to the same genet (Arnaud-Haond 
et al., 2007). In addition, distinct MLGs that differ at a single locus, could occur in the dataset. This slight difference may be due to somatic mutations or scoring errors (Douhovnikoff and Dodd, 2003), although these distinct MLGs originate from the same reproductive event. In this case, the number of genets occurring in the dataset is over-estimated. In order to avoid this potential bias, the MLGs distinct for a single locus were screened, and the locus at which they differ was removed. On the basis of the reduced set of loci, $P_{\text {sex }}\left(F_{i s}\right)$ was re-assessed. When this second $P_{\text {sex }}\left(F_{i s}\right)$ was less than 0.01 (confirming a scoring error or a somatic mutation), the slightly different MLGs were considered to belong to the same genet, and were grouped within a single Multi-locus Lineage (MLL, ArnaudHaond et al, 2007). When $P_{\text {sex }}\left(F_{i s}\right)>0.01$, the MLGs distinct for a single locus were considered as two distinct genets. Genotypic datasets were also corrected if needed.

The clonal richness, $\mathrm{R}$, was estimated as the ratio of the number of discriminated genets with the number of sampling units:

$\mathrm{R}=(\mathrm{G}-1) /(\mathrm{N}-1)$

with $\mathrm{G}$ representing the numbers of genets discriminated for the considered location and $\mathrm{N}$ representing the number of sampling units. Using geographical coordinates, the distance (in meters) between the replicates of the same genet was assessed. The clonal sub-range CR (Alberto et al., 2005; Harada et al., 1997), corresponding the maximum distance between two replicates of the same genet, was assessed for each location. The coefficient of aggregation was also assessed as follows:

$$
A_{c}=\frac{P_{s g}-P_{s p}}{P_{s g}}
$$

with $\mathrm{P}_{\mathrm{sg}}$ being the average probability of clonal identity of all sampled colonies, and $\mathrm{P}_{\mathrm{sp}}$ being the average probability of clonal identity among pairwise nearest neighbors. Its significance was estimated after 1000 permutations. Estimations of these parameters of clonal diversity and structure were performed using Genclone 2.1 (Arnaud-Haond and Belkhir, 2007).

The assessment of genetic diversity and structure was performed using a derived dataset in which a single replicate of each distinct MLL is retained, with Genetix 4.05 (Belkhir et al., 2004). Genetic diversity within quadrats was estimated using several indices. The mean number of alleles per locus (Â) was standardized to the lowest number of sampling units collected in a quadrat (Table 1). The estimates of observed $\left(\mathrm{H}_{\mathrm{O}}\right)$ and unbiased $\left(\mathrm{H}_{\mathrm{E}}\right)$ multi-locus heterozygosity (Nei, 1978) were also calculated. The $\mathrm{F}_{\mathrm{IS}}$-statistic was also assessed and its significance was tested using a procedure of 1000 permutations. Linkage disequilibrium was assessed using the software Multilocus 1.3 (http://www.bio.ic.ac.uk/evolve/software/multilocus/) through the index $\check{\mathrm{r}}_{\mathrm{d}}$. Genetic structure among samples was estimated with $\theta$ (Weir and Cockerham, 1984), providing a value of pairwise $\mathrm{F}_{\text {st }}$ from a procedure of 1000 permutations. The number of distinct panmictic units occurring in our database was 
investigated using the Bayesian software STRUCTURE version 2.1 (Pritchard et al., 2000). Each run began with an initial burn-in of 50,000 cycles followed by 500,000 additional cycles. The number of clusters, K, varied from one to five, and five iterations for each K-value were performed. In all simulations, an admixture ancestry model and correlated allele frequency model were used. The DK criterion of Evanno et al. (2005) was assessed using STRUCTURE HARVESTER (http://taylor0.biology.ucla.edu/structureHarvester/) to choose the most likely K-value.

The aggregation of colonies belonging to the same clonal lineages was tested using the aggregation index (Arnaud-Haond et al., 2007). Spatial autocorrelation analyses were also performed including and excluding replicates, to test for the signature of clonal spatial aggregation or restriction to gene flow at the within-quadrat scale (Vekemans and Hardy, 2004). We used the kinship estimator coefficient of Loiselle $\left(\mathrm{F}_{\mathrm{ij}}\right)$, computed with Genclone 2.1, as a genetic relatedness statistic (Loiselle et al., 1995). We performed regression analyses of mean $\mathrm{F}_{\mathrm{ij}}$ against the mean geographic distance, within each of the six distance-classes. This allowed us to test the adequacy of Isolation by Distance (IBD) models in each quadrat. These analyses were first performed including all sampling units, including the clonal replicates. In this case, the spatial genetic structure (SGS) is mostly influenced by the spatial extent of clones. In a second iteration, spatial autocorrelation was assessed using a procedure of 1000 permutations, in order to include only one replicate from each MLG, at each permutation (randomly choosing one of the possible geographical coordinates). This second step aims to examine the dispersion through sexual propagules, at the within-quadrat scale. The spatial autocorrelation profile, $S_{p}$ (Vekemans and Hardy, 2004) is defined by the following:

$$
S_{p}=\frac{-b}{1-F_{(1)}}
$$

where $F_{(1)}$ equals the kinship value for the first distance class and $b$ is the slope of the regression. Values vary from zero (no limitation to gene dispersal at the scale of the sampling) to $+\infty$ (theoretical case, where the structure is maximal). Autocorrelation parameter estimations were performed with GENCLONE 2.1 (Arnaud-Haond and Belkhir, 2007). 


\section{Results}

Depending on the abundance of corals and/or restriction of dive time availability and current speed (slowing down the ROV), the duration of dives varied from about $5 \mathrm{~h}$ to $24 \mathrm{~h}$. Ten to 25 minutes were necessary to collect one colony (a mean of 17 minutes), although it should be noted that significant time was consumed when returning coral cases to or recovering them from the lift.

For $200 \times 100 \mathrm{~m}^{2}$ quadrats, the number of sampling units varied between 24 and 39 colonies for both $L$. pertusa and M. oculata (except the quadrat of Crozon Canyon where only 13 M. oculata colonies could be collected). For the half-quadrat at Guilvinec Canyon (Q2), 16 and 17 colonies were recovered of M. oculata and L. pertusa, respectively, leading to sampling density that was comparable to full quadrats.

The set of microsatellite markers used in this study distinguished all clonal lineages, with $P_{\text {sex }}\left(F_{i s}\right)$ being highly significant. Only two slightly different MLGs (a single allele) were detected, one in each of the L. pertusa and M. oculata datasets. The $P_{\text {sex }}\left(F_{i s}\right)$, assessed after having removed the concerned locus as suggested in Arnaud-Haond et al. (2007), was also significant, and these MLGs were therefore considered as derived from the same event of sexual reproduction but distinct only through one somatic mutation or scoring error, and subsequently merged into a single MLL. We have designated all discriminated genets under the label "MLL".

The levels of clonal richness were comparable and very high for both species, indicating a low rate of clonality at the scale analyzed. The clonal richness ranged from 0.87 to 1 for L. pertusa (Table 1 ) and from 0.89 to 1 for M. oculata (Table 2). Within the L. pertusa dataset (177 sampling units, 164 distinct MLLs discriminated), only 13 MLLs with replicates were found. The distance between replicates varied from $0.0 \mathrm{~m}$ to $151.9 \mathrm{~m}$, in the quadrat 1 of Petite Sole Canyon (clonal subrange, Table 1). Yet, most distances among identical MLL were considered as null (see Table 1), indicating that the replicates were collected on distinct colonies adjacent to each other and sharing the same GPS coordinates. Therefore, real distances did not exceed one meter (see material and methods). Similarly, within the M. oculata dataset (197 sampling units, 187 distinct MLLs discriminated), eight lineages with replicates were detected. Five clusters or pairs of MLL replicates shared the same GPS coordinates. For the three remaining genets, the distance ranged from $10.8 \mathrm{~m}$ (quadrat 1 of the Guilvinec Canyon) to $79.4 \mathrm{~m}$ (quadrat 1 of the Petite Sole Canyon).

For both species, a strong homogeneity of the values of allelic richness and heterozygosity was observed among sites. Standardized allelic richness varies from 11.9 to 13.9 and from 4.7 to 5.2 alleles per locus for L. pertusa and M. oculata, respectively (Tables 1 and 2). Such a homogeneous distribution of diversity was also seen for both observed and expected heterozygosities (Table 1 and 2). Departures from HWE were variable, with $F_{I S}$ values ranging from null to 0.12 and 0.19 ( $p<$ 
0.001) for L. pertusa and M. oculata respectively (Tables 1 and 2), while linkage disequilibrium was higher in L. pertusa.

The clonal aggregation was significant and similar for both species in each reef where clonal replicates were sampled, with one exception (Petite Sole quadrate 1 for both species, see Table 1), supporting rather systematic spatial aggregation of clonal colonies. When including replicates, three significant patterns of spatial autocorrelation were detected for L. pertusa populations and one for M. oculata populations (Tables 1 and 2, column $\mathrm{S}_{\mathrm{p} 1}$ ). Yet, when excluding replicates, no significant result was found for L. pertusa, and the M. oculata population from Petite Sole Canyon, quadrat 1, was the only population to show a significant $S_{p 2}$-value $\left(S_{p 2}=0.303 ; p=0.046\right.$, Figure 3).

Two contrasting patterns of genetic structuring were obtained for the two species of corals at the regional scale. A weak genetic structure occurred among $L$. pertusa populations, $F_{\mathrm{st}}$-values were generally low and non-significant (Table 3). In contrast, stronger genetic differentiation was observed among M. oculata populations (Table 3). Congruent results were obtained from Bayesian structuring analyses. No significant clustering of $L$. pertusa data was detected by STRUCTURE, and the most likely number of cluster was estimated to be one by STRUCTURE HARVESTER (Figure 4). For the M. oculata data set, the Evanno method indicated that the most likely number of clusters was four (Figure 5). Interestingly, the clustering of M. oculata populations matched with geography, where the blue, red, yellow and green clusters coincided, respectively, with the canyons of Le Croisic, Crozon, Morgat and Petite Sole (Figure 5). The samples from Le Guilvinec formed a less defined group characterized by admixture between the two genetic backgrounds found respectively in Petite Sole and Crozon. 


\section{Discussion}

The standardized sampling approach tested here allowed for the most comprehensive analysis of clonality to date in two important, reef-building CWC species. The collection of representative data at each of the five reefs studied revealed the cold-water corals L. pertusa and M. oculata exhibit mostly low levels of clonality. The high values of clonal richness obtained for both species indicate that sexual reproduction is dominant, and only a small proportion of colonies originate from clonal reproduction. Generally, the clonality of CWC seems to have a predominantly local incidence (i.e. a clonal extent around a meter), as the few colonies found to belong to the same clonal lineage were generally aggregated.

The values of clonal richness we assessed in this work (between 0.87 and 1 for both species) are generally in agreement with those assessed by Morrison et al., (2011), for L. pertusa at a larger scale ( $\mathrm{R}$ varying from 0.73 to 1 ). The sampling scheme adopted by these authors, mostly using submersible or ROV, also devoted particular attention to the distance between sampled colonies ( $>5$ meters) to limit the collection of replicates of the same clone, whereas our approach aimed at tackling clonality as well as genetic diversity and favored a random distribution of samples. This former study and the present work, however, both showed much higher, and less variable, levels of clonal diversity than those reported by Le Goff-Vitry et al., (2004) for European L. pertusa reefs, where the genotypic richness varied from 0.12 (Darwin Mounds) to the maximal values of 1 for several others locations (but see the Table 2 of Le Goff-Vitry et al., 2004, for details). These discrepancies, sometimes large, may be attributed to regional differences in the rate of clonality. Yet, this seems unlikely, as no such regional differences among the Bay of Biscay (the present work), the Gulf of Mexico and the Southeastern U.S. coast (Morrison et al., 2011) were observed. Assessment of the clonality in European L. pertusa populations may have been biased by the sampling of colonies through trawling and/or the use of grab. Notably, the Darwin Mounds province was sampled by trawling (Table 1 in Le Goff-Vitry et al., 2004). The blind collection of samples in this pioneer study leads us to suggest that the fragmentation of colonies during sampling and their incidental duplication in the dataset contributed to artificially low $\mathrm{R}$ values and led to an overestimation of asexuality. It is notable that similar limited influence of clonality was detected for M. oculata, for which clonal and genetic structure are characterized here for the first time with molecular markers.

A recent fine-scale study of L. pertusa (Dahl et al., 2012) reported much lower values of clonal richness, despite comparable sampling. This difference in results underscores the importance of the sampling regime and/or density, which estimators of clonality are highly dependent upon (ArnaudHaond et al., 2007; Barrès et al., 2012). The lower values reported in Northern Sweden by Dahl et al, (2012) could be at first interpreted as a difference in the importance of clonal fragmentation in the Swedish reef compared to the Bay of Biscay reefs. Yet we suggest here that differences in degree of 
clonality between the studies may be due to the different grain size used for sampling. As exhaustive sampling was targeted to fully map a single reef in Dahl et al., (2012), higher local sampling density in their small scale study favored the systematic sampling of adjacent colonies that are more likely to be clonemates, either colonies remnant of a larger one that fragmented through time, or colonies issued from settlement of fallen fragments next to the original colony. In our study, where representation of sampling quadrats for reef description and comparison was pursued rather than exhaustive sampling for fine-grained mapping, the average distance among colonies was larger and sampling density lower, which has been shown to artificially induce higher clonal diversity estimates (Arnaud-Haond et al., 2007). Thus, the random sampling strategy retained here is not aimed at providing precise estimates of clonality that are best approached by the Dahl et al., (2012) exhaustive sampling strategy, but rather at estimating its comparative extent and spatial influence across reefs and species. The inter-site differences in density (number of ramets per square-meter) may represent an additional source of bias in clonality assessment (Arnaud-Haond et al., 2007; Baums et al., 2006), potentially impeding comparisons of richness among sampling sites. Indeed, for equivalent sampling effort (i.e the number of collected colonies), dense reefs lead to a lower sampling density when compared with sparse reefs, and that translates to an underestimation of clonality (see Fig. 6 in Arnaud-Haond et al., 2007). Arnaud-Haond et al., (2015), in this issue, have performed density-estimations for both L. pertusa and M. oculata, using video-records conducted during sampling sessions. Due to the high patchiness of the spatial distribution of colonies, densities appeared low on average, but highly variable at the sampling quadrat scale. In the present case, the spatial extent of clonality was low, around a meter. Such differences in density may not drastically affect our ability to compare the estimations of clonality. To this extent, the present study allows confirmation that the limited clonal rate and dispersal observed in the Swedish reef (see Fig. 3 in Dahl et al., (2012) is not specific to the reef studied and that the occurrence of clonal extension is rare and spatially localized in reefs across the Bay of Biscay.

The tropical, shallow-water coral populations seem characterized by a globally higher rate of clonality, and a larger variance of clonal richness, fluctuating between very low, almost null, and maximal values (Baums et al., 2014; Baums et al., 2006; Coffroth and Lasker, 1998; Miller and Ayre, 2004; Pinzón et al., 2012). Surface events, such as waves, storms and currents, represent potential drivers of perturbations leading to clonal fragmentation and high clonality (Baums et al., 2006). In the deep-sea, mechanical actions also represent an explanation for rare but large clonal extension events (Dahl et al., 2012). In the Bay of Biscay, the replicates of clones appear mostly aggregated (Table 1, CR and Ac). Even if two thirds of replicated MLLs in this area occurred when adjacent colonies were collected at the same sampling points, we occasionally sampled replicates of MLLs separated by large distances, between tens to hundreds of meters, as indicated by the values of clonal subrange (Tables 1 and 2). Those results are also in agreement with the previous fine-grained study of a Northern Scandinavian reefs (Dahl et al., 2012) of L. pertusa in the sense that long distances among clonal replicates were 
mostly observed here, as by Dahl et al., (2012) in trawled areas (see van den Beld et al., submitted in this issue for pictures). Therefore, it may be noted here that despite the presence of clonality, it generally does not seem to be prevalent over large distances, with the four exceptions of replicated MLGs at distances of about 50 to 150 meters (Tables 1 and 2, column D (replicates)). These results, considering the low sampling density compared to the total number of colonies present in the sampled areas, suggests that the clonality of $\mathrm{CWC}$, although scarce, may still have a local influence on population dynamics, particularly in impacted areas.

Our hypothesis of limited clonal extension is supported by the fine-grained spatial genetic structure. The clonal aggregation results demonstrate significant spatial autocorrelation patterns for three $L$. pertusa populations (Table 1, quadrats 2 of Petite Sole and Guilvinec Canyons, and Morgat Canyon) and for the M. oculata population from the quadrat 1 of Guilvinec Canyon (Table 2). Yet, when excluding clonal replicates, no significant pattern was detected, except in the quadrat 1 of Petite Sole Canyon for M. oculata (Table 2, Figure 3). Dahl et al., (2012) have suggested that 'Lophelia does not develop asexual larvae and that coral fragments are not transported over long distances'. Here, our results generally agree with this hypothesis that the recruitment of fragmented colonies remains mostly local. Yet, our sampling did not allow testing for the existence of asexual larvae that, if present, may have dispersed out of the sampling quadrats.

Finally, the lack of genetic differentiation across localities suggests large scale dispersal of sexual larvae of L. pertusa (Figure 4). Our L. pertusa results agree with previous studies that found genetic continuity along neighboring continental slope populations in both the eastern and western North Atlantic Ocean (Le Goff-Vitry et al., 2004; Morrison et al., 2011). Interestingly, more pronounced differentiation was detected among M. oculata populations (Figure 5). Our population genetic analysis of M. oculata in the Bay of Biscay supports at least four genetic units coinciding with four of the five explored canyons. Contrasting genetic structure between the two species could be due to differences in larval dispersal potential leading to distinct patterns of contemporary connectivity, a hypothesis difficult to ascertain as very few is known about the larval dispersal of CWC, particularly M. oculata. A non-mutually exclusive hypothesis is that of distinct histories of colonization due to slight differences in habitat suitability, as an inverse gradient North - South was suggested by recent studies (Arnaud-Haond et al., 2015). The geographical window of the present study being limited, additional sampling locations are required for an in-depth comparison of population dynamics and connectivity among reefs inhabited by L. pertusa and M. oculata, as well as phylogeographic studies to reconstruct their history along European coasts. 


\section{Conclusion}

Here we demonstrate the feasibility of a protocol for a standardized and randomized sampling strategy in the deep-sea. Despite the fact that it is time-consuming and requires an extensive expertise in ROV manipulation, this sampling strategy presents a twofold advantage both for understanding fine-grained biological processes, and for inferences involving species conservation and management.

Standardization of a sampling regime and density is required for reliable biological comparisons among populations. Using this sampling approach, we demonstrated comparably high levels of clonal richness for both Lophelia pertusa and Madrepora oculata at the spatial scales considered and in all reefs explored. The use of random geographical coordinates allowed for the assessment of both clonal extension- predominantly very local- and fine-scale genetic structure. The significant pattern of autocorrelation, although observed in a single case, suggests that fine-grained spatial structure due to low dispersal of larvae from the mother colony or to settlement of clouds of closely related larvae is possible, at least for M. oculata.

A standardized and geo-georeferenced sampling strategy, that proved to be realistic, may be applied for other ecological studies as management strategies require rigorous and standardized methodologies for observation and sampling, particularly in the case of environmental impact assessments.

\section{Acknowledgment}

This work was performed in the framework of the EC FP7 project 'CoralFISH' under Grant agreement no. 213144. We are deeply grateful to the whole crew, the team of Genavir whose pilot expertise made this work possible, and the scientific teams for their invaluable contributions to the BobEco cruise. We thank Lise Vauvert and Christophe Bayle for their technical help. We also wish to thank Anna Rengstorf, D.K. Coykendall, K. Briggs, the referee Iliana B. Baums, and the anonymous referee for their valuable comments on the previous version of the manuscript. Any use of trade, product, or firm names is for descriptive purposes only and does not imply endorsement by the U.S. government. 


\section{References}

Alberto, F., Gouveia, L., Arnaud-Haond, S., Perez-Llorens, J.L., Duarte, C.M., Serrao, E.A., 2005. Within-population spatial genetic structure, neighbourhood size and clonal subrange in the seagrass Cymodocea nodosa. Molecular Ecology 14 (9), 2669-2681.

Arnaud-Haond, S., Alberto, F., Teixeira, S., Procaccini, G., Serrao, E.A., Duarte, C.M., 2005. Assessing genetic diversity in clonal organisms: Low diversity or low resolution? Combining power and cost efficiency in selecting markers. Journal of Heredity 96 (4), 434-440.

Arnaud-Haond, S., Belkhir, K., 2007. GENCLONE: a computer program to analyse genotypic data, test for clonality and describe spatial clonal organization. Molecular Ecology Notes 7 (1), 15-17.

Arnaud-Haond, S., Duarte, C.M., Alberto, F., Serrao, E.A., 2007. Standardizing methods to address clonality in population studies. Molecular Ecology 16 (24), 5115-5139.

Arnaud-Haond, S., Duarte, C.M., Diaz-Almela, E., Marba, N., Sintes, T., Serrao, E.A., 2012. Implications of Extreme Life Span in Clonal Organisms: Millenary Clones in Meadows of the Threatened Seagrass Posidonia oceanica. Plos One 7 (2).

Arnaud-Haond, S., Van den Beld, I.M.J., Becheler, R., Orejas, C., Menot, L., Frank, N., Grehan, A., Bourillet, J., 2015. Two pilars for cold water coral reefs reefs along Atlantic European margins: prevalent association of Madrepora oculata to Lophelia pertusa, from reef to the colony scale. Deep Sea Research Part II: Topical Studies in Oceanography (doi:10.1016/j.dsr2.2015.07.013).

Baillon, S., Hamel, J.F., Wareham, V.E., Mercier, A., 2012. Deep cold-water corals as nurseries for fish larvae. Frontiers in Ecology and the Environment 10 (7), 351-356.

Barrès, B., Dutech, C., Andrieux, A., Halkett, F., Frey, P., 2012. Exploring the role of asexual multiplication in poplar rust epidemics: impact on diversity and genetic structure. Molecular Ecology 21, 4996-5008.

Baums, I.B., Devlin-Durante, M., Laing, B.A.A., Feingold, J., Smith, T., Bruckner, A., Monteiro, J., 2014. Marginal coral populations: the densest known aggregation of Pocillopora in the Galápagos Archipelago is of asexual origin. Frontiers in Marine Science 1 (59), 1-11.

Baums, I.B., Miller, M.W., Hellberg, M.E., 2006. Geographic variations in clonal structure in a reefbuilding caribbean coral, Acropora palmata. Ecological Monographs 76(4), 503-519.

Becheler, R., Diekmann, O., Hily, C., Moalic, Y., Arnaud-Haond, S., 2010. The concept of population in clonal organisms: mosaics of temporally colonized patches are forming highly diverse meadows of Zostera marina in Brittany. Molecular Ecology 19 (12), 2394-2407.

Belkhir, K., Borsa, P., Chikhi, L., Raufaste, N., Bonhomme, F., 2004. GENETIX 4.05, logiciel sous Windows TM pour la génétique des populations. Laboratoire Génome, Populations, Interactions, CNRS UMR 5000, Université de Montpellier II, Montpellier.

Blanquer, A., Uriz, M.-J., Caujapé-Castells, J., 2009. Small-scale spatial genetic structure in Scopalina lophyropoda, an encrusting sponge with philopatric larval dispersal and frequent fission and fusion events. Marine Ecology Progress Series 380, 95-102.

Boulay, J.N., Cortès, J., Nivia-Ruiz, J., Baums, I.B., 2012. Genotypic diversity of the reef-building coral Porites lobata (Dana, 1846) (Scleractinia: Poritidae) at Cocos Island National Park, Costa Rica. Journal of Tropical Biology 60, 279-292.

Cairns, S., 1994. Scleractinia of the temperate North Pacific. Smithsonian contributions to zoology, Smithsonian Institution Press Washington D.C. 557.

Cathalot, C., Van Oevelen, D., Cox, T., Kutti, T., Lavaleye, M., Duineveld, G., Meysman, F.J.R., 2015. Cold-water coral reefs and adjacent sponge grounds: Hotspots of benthic respiration and organic carbon cycling in the deep sea. Frontiers in Marine Science 2 (37), 1-12.

Coffroth, M.A., Lasker, H.R., 1998. Population structure of a clonal gorgonian coral: the interplay between clonal reproduction and disturbance. Evolution 52(2), 379-393.

Costantini, F., Fauvelot, C., Abbiati, M., 2007a. Fine-scale genetic structuring in Corallium rubrum: evidence of inbreeding and limited effective larval dispersal. Marine Ecology Progress Series 340, 109-119. 
Costantini, F., Fauvelot, C., Abbiati, M., 2007b. Genetic structuring of the temperate gorgonian coral (Corallium rubrum) across the western Mediterranean Sea revealed by microsatellites and nuclear sequences. Molecular Ecology 16 (24), 5168-5182.

Dahl, M.P., Pereyra, R.T., Lundalv, T., Andre, C., 2012. Fine-scale spatial genetic structure and clonal distribution of the cold-water coral Lophelia pertusa. Coral Reefs 31 (4), 1135-1148.

Douhovnikoff, V., Dodd, R.S., 2003. Intra-clonal variation and a similarity threshold for identification of clones: application to Salix exigua using AFLP molecular markers. Theoretical and Applied Genetics 106 (7), 1307-1315.

Douhovnikoff, V., McBride, J.R., Dodd, R.S., 2005. Salix exigua clonal growth and population dynamics in relation to disturbance regime variation. Ecology 86 (2), 446-452.

Doyle, J.J., Doyle, J.L., 1988. Natural interspecific hybridization in eastern north-american Claytonia. American Journal of Botany 75 (8), 1238-1246.

Eriksson, O., 1993. Dynamics of genets in clonal plants. Trends in Ecology \& Evolution 8 (9), 313 316.

Evanno, G., Regnaut, S., Goudet, J., 2005. Detecting the number of clusters of individuals using the software STRUCTURE: a simulation study. Molecular Ecology 14 (8), 2611-2620.

Fossa, J.H., Mortensen, P.B., Furevik, D.M., 2002. The deep-water coral Lophelia pertusa in Norwegian waters: distribution and fishery impacts. Hydrobiologia 471, 1-12.

Foster, N.L., Baums, I.B., Mumby, P.J., 2007. Sexual vs. asexual reproduction in an ecosystem engineer: the massive coral Montastraea annularis. Journal of Animal Ecology 76, 384-391.

Freiwald, A., 2002. Reef-forming cold-water corals. Ocean Margin Systems, Springer. Heidelberg.

Freiwald, A., Fossa, J.H., Grehan, A., Koslow, T., Roberts, J.M., 2004. Cold-water coral reefs. UNEPWCMC, Cambridge.

Freiwald, A., Roberts, J.M., 2005. Cold-water corals and ecosystems - Preface.

Freiwald, A., Wilson, J.B., Henrich, R., 1999. Grounding Pleistocene icebergs shape recent deepwater coral reefs. Sedimentary Geology 125 (1), 1-8.

Hammerli, A., Reusch, T.B.H., 2003. Genetic neighbourhood of clone structures in eelgrass meadows quantified by spatial autocorrelation of microsatellite markers. Heredity 91 (5), 448-455.

Harada, Y., Kawano, S., Iwasa, Y., 1997. Probability of clonal identity: inferring the relative success of sexual versus clonal reproduction from spatial genetic patterns. Journal of Ecology 85 (5), 591-600.

Hunter, C.L., 1993. Genotypic variation and clonal structure in coral populations with different disturbance histories. Evolution 47, 1213-1228.

Le Goff-Vitry, M.C., Pybus, O.G., Rogers, A.D., 2004. Genetic structure of the deep-sea coral Lophelia pertusa in the northeast Atlantic revealed by microsatellites and internal transcribed spacer sequences. Molecular Ecology 13 (3), 537-549.

Loiselle, B.A., Sork, V.L., Nason, J., Graham, C., 1995. Spatial genetic structure of a tropical understory shrub, Psychotria officinalis (Rubiaceae). American Journal of Botany 82, 1420-1425.

Miller, K.J., Ayre, D.J., 2004. The role of sexual and asexual reproduction in structuring high latitude populations of the reef coral Pocillopora damicornis. Heredity 92, 557-568.

Morrison, C.L., Eackles, M.S., Johnson, R.L., King, T.L., 2008. Characterization of 13 microsatellite loci for the deep-sea coral, Lophelia pertusa (Linnaeus 1758), from the western North Atlantic Ocean and Gulf of Mexico. Molecular Ecology Resources 8 (5), 1037-1039.

Morrison, C.L., Ross, S.W., Nizinski, M.S., Brooke, S., Jaernegren, J., Waller, R.G., Johnson, R.L., King, T.L., 2011. Genetic discontinuity among regional populations of Lophelia pertusa in the North Atlantic Ocean. Conservation Genetics 12 (3), 713-729.

Nei, M., 1978. Estimation of average heterozygosity and genetic distance from small number of individuals. Genetics 89 (3), 583-590.

Parks, J.C., Werth, C.R., 1993. A study of spatial features of clones in a population of bracken fern, Pteridium aquilinium (Dennstaedtiaceae). American Journal of Botany 80 (5), 537-544.

Pawlowski, J., Fahrni, J., Lecroq, B., Longet, D., Cornelius, N., Excoffier, L., Cedhagen, T., Gooday, A.J., 2007. Bipolar gene flow in deep-sea benthic foraminifera. Molecular Ecology 16, 4089-4096.

Pinzón, J.H., Reyes-Bonilla, H., Baums, I.B., LaJeuness, T.C., 2012. Contrasting clonal structure among Pocillopora (Scleractinia) communities at two environmentally distinct sites in the Gulf of California. Coral Reefs 31, 765-777. 
Pritchard, J.K., Stephens, M., Donnelly, P., 2000. Inference of Population Structure Using Multilocus Genotype Data. Genetics 155, 945-959.

Roberts, J.M., Wheeler, A.J., Freiwald, A., 2006. Reefs of the deep: The biology and geology of coldwater coral ecosystems. Science 312 (5773), 543-547.

Roberts, S., Hirshfield, M., 2004. Deep-sea corals: out of sight, but no longer out of mind. Frontiers in Ecology and the Environment 2 (3), 123-130.

Rogers, A.D., 1999. The biology of Lophelia pertusa (LINNAEUS 1758) and other deep-water reefforming corals and impacts from human activities. International Review of Hydrobiology 84 (4), 315 406.

Ross, S.W., Nizinski, M.S., 2007. State of deep coral ecosystems in the US southeast region: Cape Hatteras to southeastern Florida. The State of Deep Coral Ecosystems of the United States, 233-270.

Schmid, B., Harper, J.L., 1985. Clonal growth in grassland perennials: density and pattern-dependant competition between olants with different growth forms. Journal of Ecology 73 (3), 793-808.

Shurin, J.B., Cottenie, K., Hillebrand, H., 2009. Spatial autocorrelation and dispersal limitation in freshwater organisms. Oecologia 159, 151-159.

van den Beld, I.M.J., Guillaumont, B., Menot, L., Bayle, C., Arnaud-Haond, S., J-F., B., submitted. Marine litter in submarine canyons of the Bay of Biscay.

Van Dover, C.L., German, C.R., Speer, K.G., Parson, L.M., Vrijenhoek, R.C., 2002. Evolution and Biogeography of Deep-Sea Vent and Seep Invertebrates. Science 295, 1253-1257.

Vekemans, X., Hardy, O.J., 2004. New insights from fine-scale spatial genetic structure analyses in plant populations. Molecular Ecology 13 (4), 921-935.

Vrijenhoek, R.C., 1997. Gene Flow and Genetic Diversity in Naturally Fragmented Metapopulations of Deep-Sea Hydrothermal Vent Animals. Journal of Heredity 88(4), 285-293.

Weir, B.S., Cockerham, C.C., 1984. Estimating F-statistics for the analysis of population-structure. Evolution 38 (6), 1358-1370.

Won, Y., Young, C.R., Lutz, R.A., Vrijenhoek, R.C., 2003. Dispersal barriers and isolation among deep-sea mussel populations (Mytilidae: Bathymodiolus) from eastern Pacific hydrothermal vents. Molecular Ecology 12, 169-184.

Zibrowius, H., 1980. Les scléractiniaires de la Méditerranée et de l'Atlantique nord-oriental. Mémoires de l'Institut océanographique, Monaco. 


\section{Legends of tables and figures}

Table 1 Clonal and genetic diversities of Lophelia pertusa populations assessed using 7 microsatellite markers. N, number of sampling units, corresponding to one colony; G, number of detected MLGs; R, the clonal richness; $\mathrm{CR}$, the clonal subrange in meter; $\mathrm{D}$ (replicates), the distances between all pairs of replicates; $\hat{A}(16)$ the allelic richness standardized for 16 sampling units; $H_{e}$ and $H_{0}$, expected and observed heterozygosity, $\mathrm{F}_{\mathrm{IS}}$-statistic for departure to Hardy-Weinberg equilibrium, $\check{\mathrm{r}}_{\mathrm{d}}$ a measure of linkage disequilibrium and $\mathrm{S}_{\mathrm{p} 1}$ and $\mathrm{S}_{\mathrm{p} 2}$ statistic of spatial autocorrelation using the Loiselle's coefficient including and excluding clonal replicates, respectively; $\mathrm{A}_{\mathrm{c}}$. the coefficient of aggregation of clonal replicates. *: $\mathrm{p}<0.05 ; * *: \mathrm{p}<0.01 ; * * * \mathrm{p}<0.001$.

Table 2 Clonal and genetic diversities of Madrepora oculata populations, assessed using 6 microsatellite markers. N, number of sampling units, corresponding to one colony; G, number of detected MLGs; R, the clonal richness; CR, the clonal subrange in meter; $\mathrm{D}$ (replicates), the distances between all pairs of replicates; $\hat{A}(17)$ the allelic richness standardized for 17 sampling units; $H_{e}$ and $\mathrm{H}_{\mathrm{o}}$, expected and observed heterozygosity, $\mathrm{F}_{\mathrm{IS}}$-statistic for departure to Hardy-Weinberg equilibrium, $\check{\mathrm{r}}_{\mathrm{d}}$ a measure of linkage disequilibrium and $\mathrm{S}_{\mathrm{p} 1}$ and $\mathrm{S}_{\mathrm{p} 2}$ statistic of spatial autocorrelation using the Loiselle's coefficient including and excluding clonal replicates, respectively; $A_{c}$.the coefficient of aggregation of clonal replicates. *: $\mathrm{p}<0.05 ; * *: \mathrm{p}<0.01 ; * * * \mathrm{p}<0.001$.

Table 3 Pairwise Fst-matrix using the $\theta$ estimator, after 1000 permutations, among Lophelia pertusa populations (above diagonal) and among Madrepora oculata populations (below diagonal). *: $\mathrm{p}<$ $0.05 ; * *: \mathrm{p}<0.1$ and $* * *: \mathrm{p}<0.001$.

Figure 1 Canyons sampling locations in the Bay of Biscay in the NE Atlantic Ocean. These reefs are colonized by both Lophelia pertusa and Madrepora oculata. Canyons of: le Croisic (Crsc); le Guilvinec (Guil); Morgat (Mrg); Crozon (Crz); Petite Sole (PS).

Figure 2 Sampling strategy and logistical means deployed. A. Mapping of the sampling quadrat positioned in the Guilvinec Canyon, and positions of randomly generated coordinates (orange dots). Red dots correspond to the corrected positions where Lophelia pertusa and Madrepora oculata were actually collected. B. The ROV Victor 6000, used during the BobEco cruise. It is equipped with lights and camera, as well as manipulators for sampling. One of three coral cases is placed on the bottom of the ROV. C. A colony of L. pertusa is placed in the Box « A1» of the coral case « A ». On board, 
scientists noted the corresponding geographical coordinates. D. The lift used to retrieve the coral cases. E. The articulated manipulator arm of the ROV during sampling.

Figure 3 Autocorrelation patterns in the Petite Sole, using the Loiselle's kinship coefficient. Black dots: clonal replicates included. Grey dots: replicates excluded. Values of Sp-statistics were assessed without replicates. All other values are available in the tables 1 and 2.

Figure 4 Bayesian clustering of Lophelia pertusa individuals from STRUCTURE analysis. Within bar-plots, each individual is represented by a vertical bar partitioned into colored sub-bars whose lengths are proportional to its estimated probability of membership for the $\mathrm{K}$ clusters. The plots on the right correspond to the mean of estimated "log probability of data" for each value of $\mathrm{K}$ (on the top) and the $\Delta \mathrm{K}$ of Evanno's method based on the rate of change in the log probability of data (on the bottom). No significant genetic structuring was detected in our dataset; the most likely number of clusters is $(\mathrm{K})=1$.

Figure 5 Bayesian clustering of Madrepora oculata individuals from STRUCTURE analysis. Within bar-plots, each individual is represented by a vertical bar partitioned into colored sub-bars whose lengths are proportional to its estimated probability of membership for the K clusters. The plots on the right correspond to the mean of estimated "log probability of data" for each value of $\mathrm{K}$ (on the top) and the $\Delta \mathrm{K}$ of Evanno's method based on the rate of change in the log probability of data (on the bottom). Four genetic units were detected from our dataset, as STRUCTURE HARVESTER outputs estimated that $\mathrm{K}=4$ was the most likely number of clusters. The structure coincided with geography. 
Table 1 Clonal and genetic diversities of Lophelia pertusa populations assessed using 7 microsatellite markers. N, number of sampling units, corresponding to one colony; G, number of detected MLGs; R, the clonal richness; $\mathrm{CR}$, the clonal subrange in meter; $\mathrm{D}$ (replicates), the distances between all pairs of replicates; $\hat{A}(16)$ the allelic richness standardized for 16 sampling units; $H_{e}$ and $H_{0}$, expected and observed heterozygosity, $\mathrm{F}_{\mathrm{IS}}$-statistic for departure to Hardy-Weinberg equilibrium, $\breve{\mathrm{r}}_{\mathrm{d}}$ a measure of linkage disequilibrium and $S_{\mathrm{p} 1}$ and $S_{\mathrm{p} 2}$ statistic of spatial autocorrelation using the Loiselle's coefficient including and excluding clonal replicates, respectively; $\mathrm{A}_{\mathrm{c}}$.the coefficient of aggregation of clonal replicates. $*$ : $\mathrm{p}<0.05 ; * * \mathrm{p}<0.01 ; * * *: \mathrm{p}<0.001$.

\begin{tabular}{|c|c|c|c|c|c|c|c|c|c|c|c|c|c|}
\hline \multirow{2}{*}{ Location } & \multicolumn{5}{|c|}{ Clonal architecture } & \multicolumn{3}{|c|}{ Genetic diversity } & \multirow[b]{2}{*}{ FIS } & \multirow[b]{2}{*}{ rd } & \multicolumn{3}{|c|}{ SGS } \\
\hline & $\mathbf{N}$ & G & $\mathbf{R}$ & CR & $\begin{array}{c}\mathrm{D} \\
\text { (replicats) }\end{array}$ & $\mathrm{He}$ & Ho & $\begin{array}{c}\text { Â(16 } \\
\text { ) }\end{array}$ & & & $\begin{array}{c}\text { Sp1 } \\
(* 1000)\end{array}$ & $\begin{array}{c}\text { Sp2 } \\
(* 1000)\end{array}$ & Ac \\
\hline Croisic Canyon Q1 & $\begin{array}{l}3 \\
9\end{array}$ & $\begin{array}{l}3 \\
6\end{array}$ & $\begin{array}{c}0.9 \\
2\end{array}$ & 98.1 & $\begin{array}{c}0.0 / 0.0 / 98 \\
.1\end{array}$ & $\begin{array}{c}0.89 \pm \\
0.08\end{array}$ & $\begin{array}{c}0.83 \pm \\
0.11\end{array}$ & $\begin{array}{c}13.7 \\
7\end{array}$ & $0.08^{* * *}$ & $\begin{array}{l}0.035^{*} \\
*\end{array}$ & 0.029 & 0.018 & $0,125 * * *$ \\
\hline $\begin{array}{c}\text { Guilvinec Canyon } \\
\text { Q1 }\end{array}$ & $\begin{array}{l}2 \\
4\end{array}$ & $\begin{array}{l}2 \\
3\end{array}$ & $\begin{array}{c}0.9 \\
6\end{array}$ & 0.0 & 0 & $\begin{array}{c}0.88 \pm \\
0.07\end{array}$ & $\begin{array}{c}0.87 \pm \\
0.07\end{array}$ & $\begin{array}{c}13.2 \\
4\end{array}$ & 0.04 & -0.004 & 0.007 & -0.085 & $0.122^{* * *}$ \\
\hline $\begin{array}{l}\text { Guilvinec Canyon } \\
\text { Q2 }\end{array}$ & $\begin{array}{l}1 \\
6\end{array}$ & $\begin{array}{l}1 \\
4\end{array}$ & $\begin{array}{c}0.8 \\
7\end{array}$ & 17.4 & $0.0 / 17.4$ & $\begin{array}{c}0.86 \pm \\
0.08\end{array}$ & $\begin{array}{c}0.89 \pm \\
0.11\end{array}$ & $\begin{array}{c}12.0 \\
0\end{array}$ & 0.00 & $\begin{array}{l}0.190^{*} \\
* *\end{array}$ & $0.973^{*}$ & 0.207 & $0.185^{*}$ \\
\hline Morgat Canyon Q1 & $\begin{array}{l}2 \\
7\end{array}$ & $\begin{array}{l}2 \\
4\end{array}$ & $\begin{array}{c}0.8 \\
8\end{array}$ & 0.0 & $\begin{array}{c}0.0 / 0.0 / 0 \\
0 /\end{array}$ & $\begin{array}{c}0.87 \pm \\
0.08\end{array}$ & $\begin{array}{c}0.89 \pm \\
0.12\end{array}$ & $\begin{array}{c}13.4 \\
7\end{array}$ & 0.00 & $\begin{array}{l}0.124^{*} \\
* *\end{array}$ & $0.284^{* *}$ & 0.041 & '0.154** \\
\hline Crozon Canyon Q1 & $\begin{array}{l}1 \\
3\end{array}$ & $\begin{array}{l}1 \\
3\end{array}$ & $\begin{array}{c}1.0 \\
0\end{array}$ & - & - & $\begin{array}{c}0.84 \pm \\
0.09\end{array}$ & $\begin{array}{c}0.78 \pm \\
0.14\end{array}$ & $\begin{array}{c}11.8 \\
6\end{array}$ & $0.12^{* *}$ & $\begin{array}{l}0.236 * \\
* *\end{array}$ & 0.018 & 0.018 & - \\
\hline $\begin{array}{l}\text { Petite Sole Canyon } \\
\text { Q1 }\end{array}$ & $\begin{array}{l}2 \\
7\end{array}$ & $\begin{array}{l}2 \\
5\end{array}$ & $\begin{array}{c}0.9 \\
2\end{array}$ & $\begin{array}{c}151 . \\
9\end{array}$ & $\begin{array}{c}23.2 / 151 \\
9\end{array}$ & $\begin{array}{c}0.87 \pm \\
0.09\end{array}$ & $\begin{array}{c}0.84 \pm \\
0.12\end{array}$ & $\begin{array}{c}13.6 \\
1\end{array}$ & $0.06 * *$ & $\begin{array}{l}0.066^{*} \\
* *\end{array}$ & -0.075 & -0.074 & 0.032 \\
\hline $\begin{array}{l}\text { Petite Sole Canyon } \\
\text { Q2 }\end{array}$ & $\begin{array}{l}3 \\
1\end{array}$ & $\begin{array}{l}2 \\
9 \\
\end{array}$ & $\begin{array}{c}0.9 \\
3\end{array}$ & 0.0 & $\begin{array}{c}0.0 / 0.0 / 0 . \\
0\end{array}$ & $\begin{array}{c}0.89 \pm \\
0.06\end{array}$ & $\begin{array}{c}0.86 \pm \\
0.11\end{array}$ & $\begin{array}{c}13.8 \\
6 \\
\end{array}$ & $0.06 * *$ & -0.003 & $0.221^{*}$ & 0.036 & $0.123^{* * *}$ \\
\hline
\end{tabular}


Table 2 Clonal and genetic diversities of Madrepora oculata populations, assessed using 6 microsatellite markers. $\mathrm{N}$, number of sampling units, corresponding to one colony; $\mathrm{G}$, number of detected MLGs; R, the clonal richness; $\mathrm{CR}$, the clonal subrange in meter; $\mathrm{D}$ (replicates), the distances between all pairs of replicates; $\hat{A}(17)$ the allelic richness standardized for 17 sampling units; $H_{e}$ and

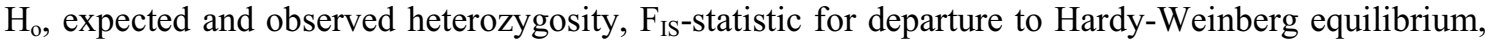
$\check{\mathrm{r}}_{\mathrm{d}}$ a measure of linkage disequilibrium and $\mathrm{S}_{\mathrm{p} 1}$ and $\mathrm{S}_{\mathrm{p} 2}$ statistic of spatial autocorrelation using the Loiselle's coefficient including and excluding clonal replicates, respectively; $\mathrm{A}_{\mathrm{c}}$.the coefficient of aggregation of clonal replicates. *: $\mathrm{p}<0.05$; $^{* *}$ : $\mathrm{p}<0.01 ; * *$ : $\mathrm{p}<0.001$.

\begin{tabular}{|c|c|c|c|c|c|c|c|c|c|c|c|c|c|}
\hline \multirow{2}{*}{ Location } & \multicolumn{5}{|c|}{ Clonal architecture } & \multicolumn{3}{|c|}{ Genetic diversity } & \multirow[b]{2}{*}{ FIS } & \multirow[b]{2}{*}{ rd } & \multirow[b]{2}{*}{$\begin{array}{c}\text { Sp1 } \\
(* 1000)\end{array}$} & \multicolumn{2}{|l|}{ SGS } \\
\hline & N & G & $\mathbf{R}$ & CR & $\begin{array}{c}\mathrm{D} \\
\text { (replicats) }\end{array}$ & $\mathrm{He}$ & Ho & $\begin{array}{c}\hat{A}(17 \\
)\end{array}$ & & & & $\begin{array}{c}\text { Sp2 } \\
(* 1000)\end{array}$ & Ac \\
\hline Croisic Canyon Q1 & $\begin{array}{l}3 \\
9\end{array}$ & $\begin{array}{l}3 \\
9\end{array}$ & 1 & - & - & $\begin{array}{c}0.66 \pm \\
0.10\end{array}$ & $\begin{array}{c}0.67 \pm \\
0.10\end{array}$ & 5.07 & 0.05 & $0.052^{* *}$ & 0.041 & 0.026 & - \\
\hline $\begin{array}{c}\text { Guilvinec Canyon } \\
\text { Q1 }\end{array}$ & $\begin{array}{l}2 \\
8\end{array}$ & $\begin{array}{l}2 \\
5\end{array}$ & $\begin{array}{c}0.8 \\
9\end{array}$ & $\begin{array}{c}47 . \\
1\end{array}$ & $\begin{array}{c}0.0 / 10.8 / 4 \\
7.1\end{array}$ & $\begin{array}{l}0.66 \pm \\
0.15\end{array}$ & $\begin{array}{c}0.63 \pm \\
0.26\end{array}$ & 4.70 & $0.08^{*}$ & 0.014 & $0.451^{*}$ & 0.248 & $0.136^{* *}$ \\
\hline $\begin{array}{c}\text { Guilvinec Canyon } \\
\text { Q2 }\end{array}$ & $\begin{array}{l}1 \\
7\end{array}$ & $\begin{array}{l}1 \\
6\end{array}$ & $\begin{array}{c}0.9 \\
4\end{array}$ & 0.0 & 0.0 & $\begin{array}{l}0.68 \pm \\
0.15\end{array}$ & $\begin{array}{c}0.57 \pm \\
0.30\end{array}$ & 5.17 & & 0.001 & -0.052 & -0.353 & $0.192^{* * *}$ \\
\hline Morgat Canyon Q1 & $\begin{array}{l}3 \\
0\end{array}$ & $\begin{array}{l}3 \\
0\end{array}$ & 1 & - & - & $\begin{array}{c}0.62 \pm \\
0.15\end{array}$ & $\begin{array}{l}0.57 \pm \\
0.22\end{array}$ & & $0.15^{* * *}$ & -0.007 & -0.096 & -0.100 & - \\
\hline Crozon Canyon Q1 & $\begin{array}{l}2 \\
4\end{array}$ & $\begin{array}{l}2 \\
2\end{array}$ & $\begin{array}{c}0.9 \\
1\end{array}$ & 0.0 & $0.0 / 0.0$ & $\begin{array}{c}0.59 \pm \\
0.24\end{array}$ & $\begin{array}{c}0.53 \pm \\
0.26\end{array}$ & 4.93 & $0.16^{* *}$ & 0.022 & 0.138 & -0.181 & $0.211^{* * *}$ \\
\hline $\begin{array}{l}\text { Petite Sole Canyon } \\
\text { Q1 }\end{array}$ & $\begin{array}{l}2 \\
6\end{array}$ & $\begin{array}{l}2 \\
3\end{array}$ & $\begin{array}{c}0.9 \\
2\end{array}$ & $\begin{array}{c}79 . \\
4\end{array}$ & 79.4 & $\begin{array}{c}0.64 \pm \\
0.16\end{array}$ & $\begin{array}{c}0.66 \pm \\
0.20\end{array}$ & 4.85 & 0.04 & 0.001 & 0.275 & $0.303^{*}$ & 0.031 \\
\hline $\begin{array}{l}\text { Petite Sole Canyon } \\
\text { Q2 }\end{array}$ & $\begin{array}{l}3 \\
3 \\
\end{array}$ & $\begin{array}{l}3 \\
2 \\
\end{array}$ & $\begin{array}{c}0.9 \\
7 \\
\end{array}$ & 0.0 & 0.0 & $\begin{array}{c}0.65 \pm \\
0.14\end{array}$ & $\begin{array}{c}0.61 \pm \\
0.17\end{array}$ & 5.24 & $0.16^{* * * *}$ & $0.048^{*}$ & -0.058 & -0.095 & $0.092^{* * * *}$ \\
\hline
\end{tabular}

Table 3 Pairwise Fst-matrix using the $\theta$ estimator, after 1000 permutations, among Lophelia pertusa populations (above diagonal) and among Madrepora oculata populations (below diagonal). *: $\mathrm{p}<$ $0.05 ; * *$ p $<0.1$ and $* * *: p<0.001$.

\begin{tabular}{cccccccc}
\hline & Croisic_Q1 & $\begin{array}{c}\text { Guilvinec } \\
\text { Q1 }\end{array}$ & $\begin{array}{c}\text { Guilvinec } \\
\text { Q2 }\end{array}$ & Morgat Q1 & Crozon Q1 & $\begin{array}{c}\text { Petite Sole } \\
\text { Q1 }\end{array}$ & $\begin{array}{c}\text { Petite Sole } \\
\text { Q2 }\end{array}$ \\
\hline Croisic_Q1 & - & 0.002 & 0.003 & 0.000 & $0.010^{*}$ & 0.000 & 0.000 \\
Guilvinec Q1 & $0.031^{*}$ & - & 0.008 & 0.004 & $0.020^{* *}$ & 0.002 & 0.000 \\
Guilvinec Q2 & $0.048^{* *}$ & 0.000 & - & 0.005 & $0.024^{* *}$ & 0.005 & 0.005 \\
Morgat Q1 & $0.056^{* * *}$ & $0.019^{*}$ & $0.047^{* *}$ & - & $0.013^{*}$ & 0.000 & 0.001 \\
Crozon Q1 & $0.100^{* * *}$ & $0.039^{* *}$ & $0.037^{* *}$ & $0.079^{* * *}$ & - & 0.007 & $0.015^{* *}$ \\
Petite Sole Q1 & $0.039^{* *}$ & 0.011 & $0.050^{* *}$ & $0.019^{*}$ & $0.104^{* * *}$ & - & 0.000 \\
Petite Sole Q2 & $0.032^{* *}$ & 0.008 & $0.026^{*}$ & $0.053^{* * *}$ & $0.089^{* * *}$ & 0.004 & - \\
\hline
\end{tabular}



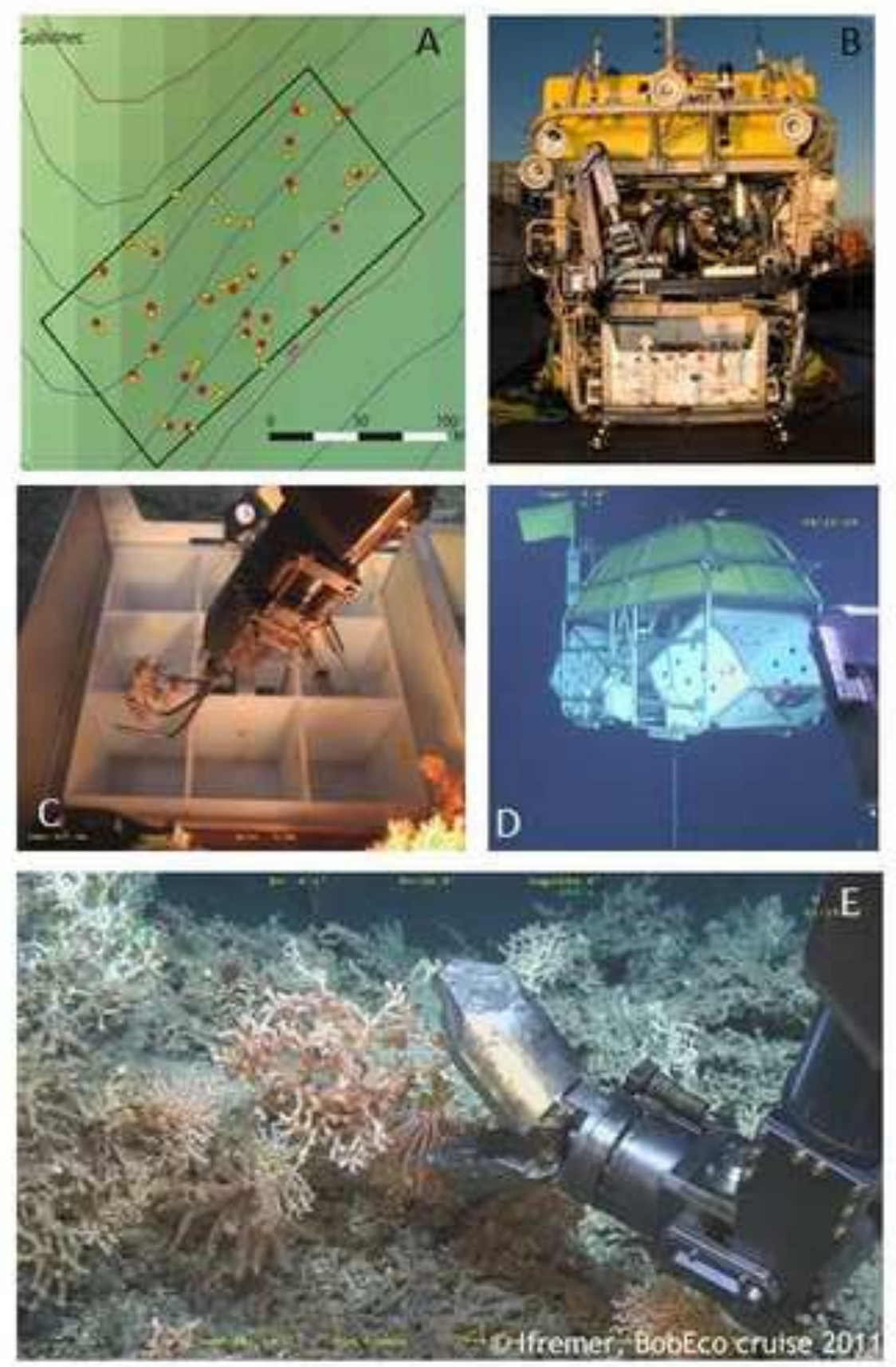

.

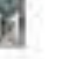



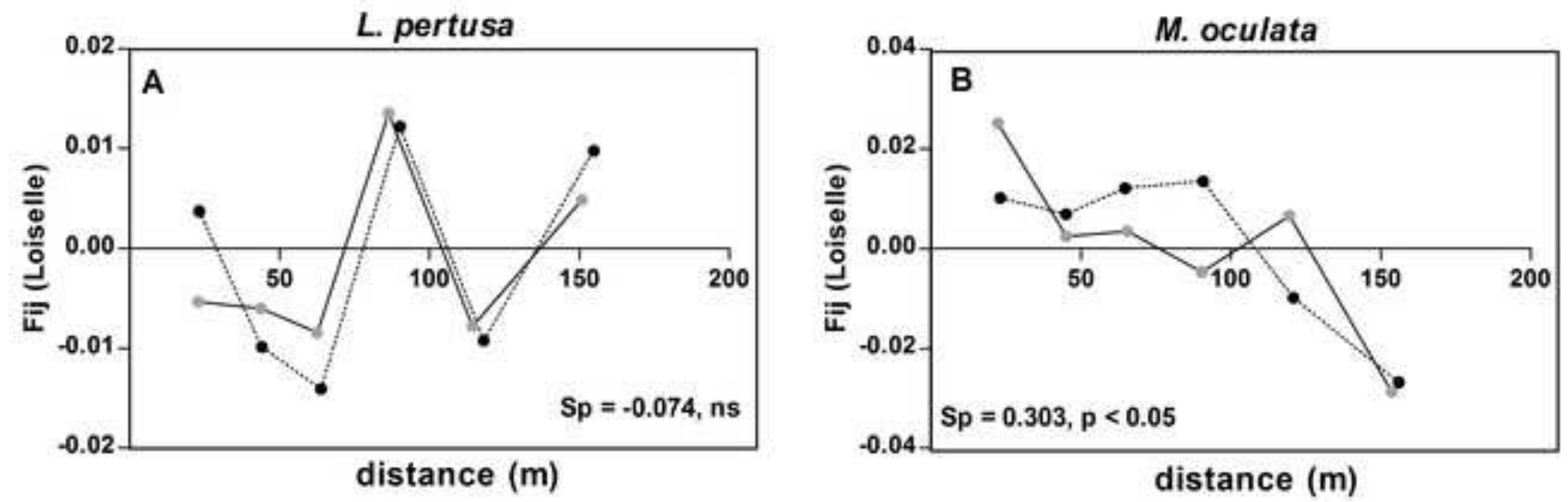

을
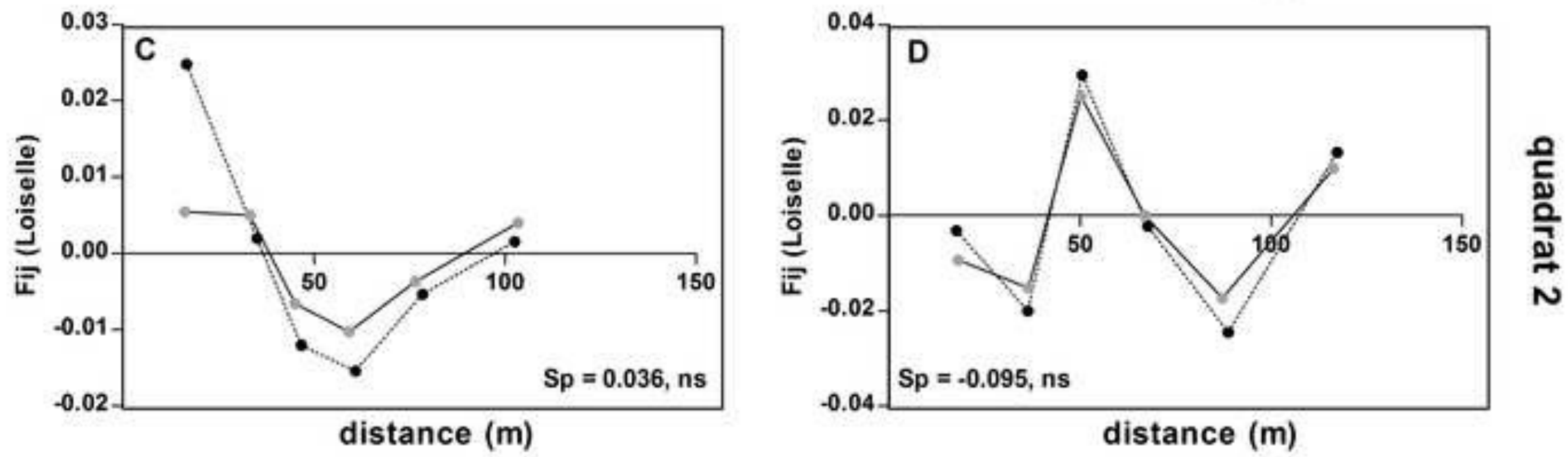

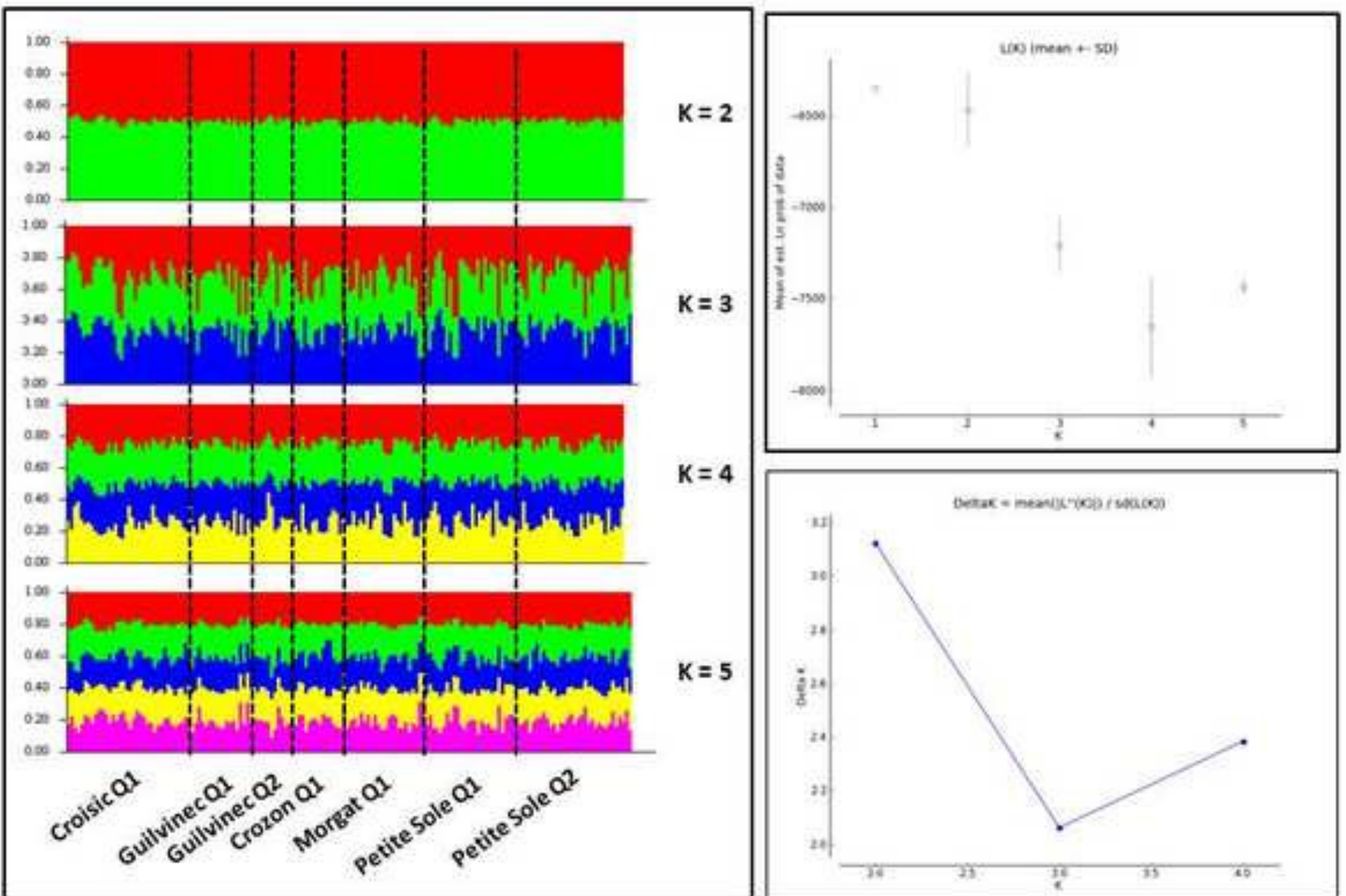

\begin{tabular}{|ccccccc|}
\hline \# K & \# Replicates & Mean LnP(K) & Stdev LnP(K) & $\operatorname{Ln}^{\prime}(\mathrm{K})$ & $\left|\operatorname{Ln}^{\prime \prime}(\mathrm{K})\right|$ & Delta K \\
\hline $\mathbf{1}$ & 3 & -6347.8 & 0.5 & $\mathrm{NA}$ & $\mathrm{NA}$ & $\mathrm{NA}$ \\
\hline $\mathbf{2}$ & 3 & -6465.5 & 199.7 & -117.7 & 623.9 & 3.12 \\
\hline $\mathbf{3}$ & 3 & -7207.1 & 144.8 & -741.6 & 298.6 & 2.06 \\
\hline $\mathbf{4}$ & 3 & -7650.1 & 277.1 & -443.0 & 661.1 & 2.39 \\
\hline $\mathbf{5}$ & 3 & -7432.0 & 36.6 & 218.1 & $\mathrm{NA}$ & NA \\
\hline \hline
\end{tabular}

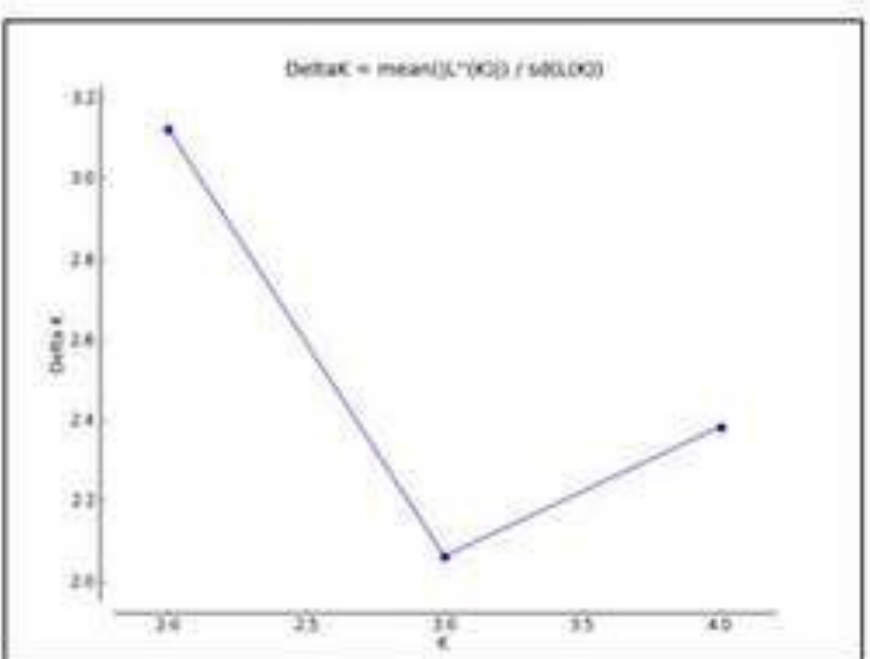



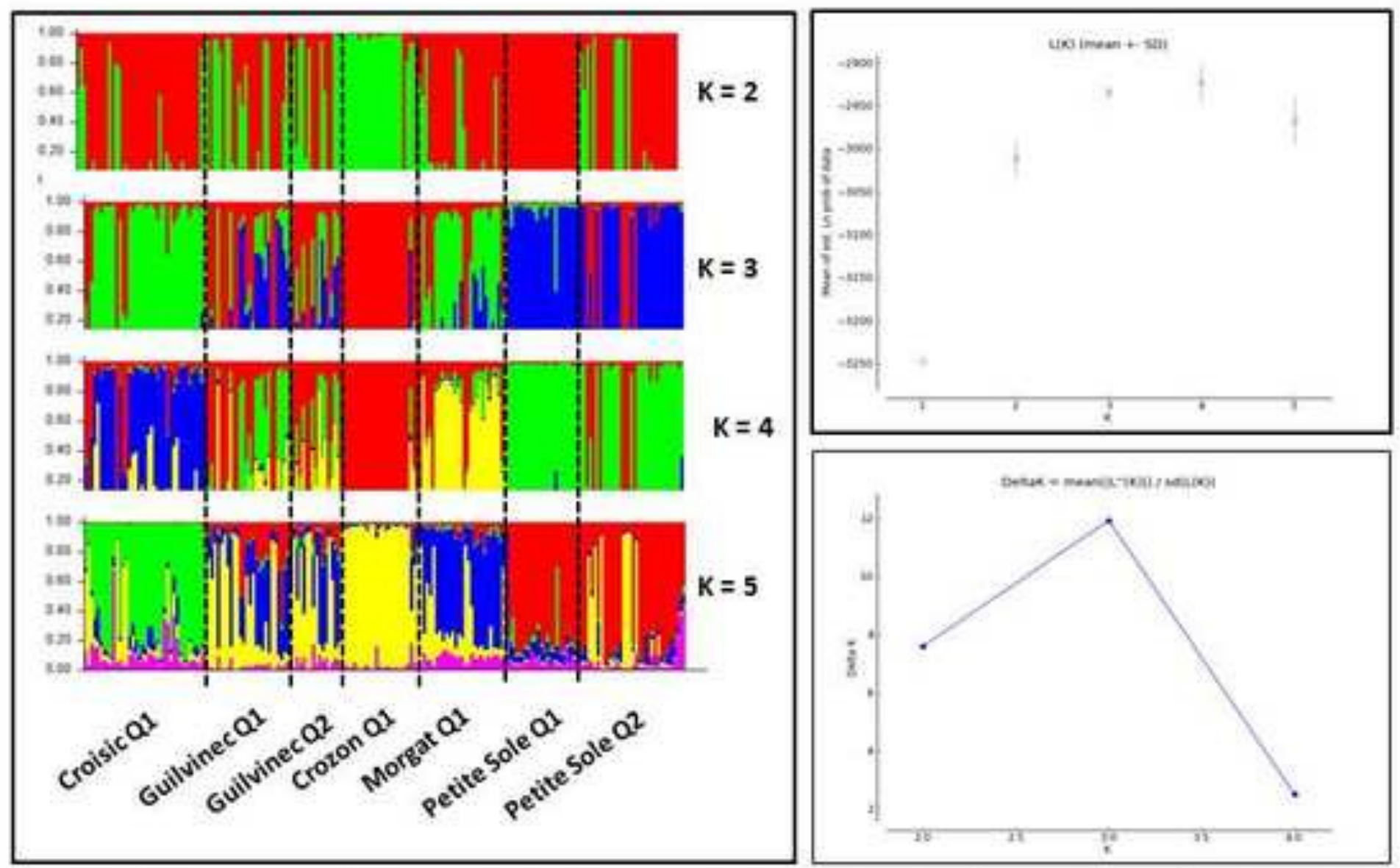

\begin{tabular}{|c|c|c|c|c|c|c|}
\hline$\# \mathrm{~K}$ & \# Replicates & Mean $\operatorname{Ln} P(K)$ & Stdev $\operatorname{Ln} P(K)$ & $\operatorname{Ln}^{\prime}(K)$ & $\left|\operatorname{Ln}^{\prime \prime}(\mathrm{K})\right|$ & Delta K \\
\hline 1 & 3 & -3247.0 & 0.1732 & NA & NA & NA \\
\hline 2 & 3 & -3010.4 & 20.9 & 236.6 & 159.5 & 7.62 \\
\hline 3 & 3 & -2933.3 & 5.5 & 77.1 & 66.2 & 11.95 \\
\hline 4 & 3 & -2922.4 & 21.9 & 10.9 & 55.2 & 2.52 \\
\hline 5 & 3 & -2966.6 & 26.8 & -44.3 & NA & NA \\
\hline
\end{tabular}




\section{Supplementary Material:}

Low incidence of clonality in cold water corals revealed through a standardized protocol adapted to deep sea sampling.

Ronan Becheler, Anne-Laure Cassone, Philippe Noël, Olivier Mouchel, Cheryl L. Morrison, Sophie Arnaud-Haond

Supplementary Table S1 Characteristics of the 6 primer pairs that amplify variable microsatellite loci in Madrepora oculata, from the five canyons in the Bay of Biscay included in this study. Locus names, GenBank Accession numbers, \#Alleles corresponds to the total number of alleles detected in our sampling set. Size Range: size range in base pairs () are shown. *: indicates the 2 loci for which an discrepancies occurred between the size range and the number of alleles, given the repeated motif. This is due to the existence of alleles with transitional length. The number of individuals successfully genotyped $(N)$ and the total number of alleles observed per sample (Alleles/sample) are provided in the Table 2 (main text). This table also reported observed and expected heterozygosities as well as departures from Hardy-Weinberg equilibrium. Annealing temperature for all loci was $56{ }^{\circ} \mathrm{C}$.

\begin{tabular}{|c|c|c|c|c|}
\hline Locus / Genbank & Primer sequence $\left(5^{\prime}-3^{\prime}\right)$ & Repeat motif & \#Alleles & Size Range \\
\hline \multirow{2}{*}{ Moc-C6 / KF944311 } & F: CGTGGCTTGTATTCTTTAGGTC & \multirow{2}{*}{$(\text { AATC })_{6}$} & \multirow{2}{*}{5} & \multirow{2}{*}{ 209-219* } \\
\hline & R: CTGGTTACGGTAGGTAGTCACC & & & \\
\hline \multirow{2}{*}{ Moc-C016 / KF944317 } & F: CTCGTGTATGACCAACATATCG & \multirow{2}{*}{$(\mathrm{AGT})_{12}$} & \multirow{2}{*}{11} & \multirow{2}{*}{$102-132$} \\
\hline & R: TGAATGAAACAATCCAGAGATG & & & \\
\hline \multirow{2}{*}{ Moc-g016 / KF944323 } & F: TGCTTCTAAATAACGATGACCC & \multirow{2}{*}{$(\mathrm{AAACC})_{7}$} & \multirow{2}{*}{14} & \multirow{2}{*}{ 149-219* } \\
\hline & R: ATGTAATTCCATGGTTTCAAGG & & & \\
\hline \multirow{2}{*}{ Moc-g025 / KF944330 } & F: GCTGATTGACTGATTGATTGAC & \multirow{2}{*}{$(\mathrm{ACCG})_{7}$} & \multirow{2}{*}{4} & \multirow{2}{*}{$104-116$} \\
\hline & R: TAAAGTTCCGAGCACAATCTG & & & \\
\hline \multirow{2}{*}{ Moc-g028 / KF944331 } & F: AATCAAAACTAGGCTGACTCCC & \multirow{2}{*}{$(\mathrm{ACAT})_{7}$} & \multirow{2}{*}{6} & \multirow{2}{*}{$178-202$} \\
\hline & R: CGTTATAGTCTCCAAGCCTCTC & & & \\
\hline \multirow{2}{*}{ Moc-C7 / KF944344 } & F: GAAATACCTGAATAGCGAAACG & \multirow{2}{*}{$(\mathrm{ACAG})_{7}$} & \multirow{2}{*}{5} & \multirow{2}{*}{$265-335$} \\
\hline & R: TTGTTTCTGTCTGTCTGTCTGC & & & \\
\hline
\end{tabular}

